\title{
Produção de currículo em uma escola do campo: uma análise sobre inclusão
}

\author{
Curriculum production in a country school: an analysis on inclusion
}

\section{Producción de lineamientos curriculares en una escuela rural: un análisis sobre inclusión}

\author{
Tânia Maria de Lima \\ Universidade Federal do Mato Grosso, Programa de Pós-Graduação em Educação em \\ Ciências e Matemática, Professora. \\ https://orcid.org/0000-0002-7478-1650 \\ Mariana Rodrigues Athayde Dormevil² \\ Escola Estadual Mal. Cândido Rondon, Professora de Língua Portuguesa. \\ https://orcid.org/0000-0001-5842-9588
}

Resumo: Este artigo põe em pauta questões relativas às experiências curriculares de uma escola do campo situada em um assentamento do município de Nobres - Mato Grosso. 0 escopo é analisar proposições curriculares que buscam articular demandas e saberes locais com orientações expressas na Base Nacional Comum Curricular, em tempos de crise na ciência. É dada centralidade aos desafios da inclusão de estudantes do campo em um contexto marcado por políticas curriculares que estabelecem padrões generalizados de saberes, competências, habilidades e de avaliação, em nome da qualidade do ensino. Busca-se amparo teórico nos estudos culturais para analisar dados extraídos de documentos e de narrativas de professores e de alunos do Ensino Médio da escola pesquisada. Argumenta-se a favor de metodologias de produção curricular que respeitem as diferenças como forma de assegurar o sentimento de pertencimento a uma instituição educativa atenta às singularidades do seu próprio espaço. Palavras-chave: Políticas curriculares. Educação do campo. Inclusão.

Abstract: This article calls into question issues related to the curricular experiences of a country school located in a settlement in Nobres, Mato Grosso, Brazil. The scope is to analyze curricular propositions that seek to articulate local demands and knowledge with orientations expressed in the National Curriculum Common Core, in times of crisis in science. It is given centrality to the challenges of the inclusion of country students in a context marked by curricular policies that establish generalized

Doutora em Educação pela Universidade Estadual de Campina; Mestre em Educação pela Universidade do Estado de Mato Grosso.

2 Mestre em Letras pela Universidade do Estado de Mato Grosso; Especialista em Coordenação Pedagógica pela Universidade Federal do Mato Grosso. 
standards of knowledge, skills and evaluation, in the name of the quality of teaching. Theoretical support is sought in cultural studies to analyze data extracted from documents and narratives of teachers that school surveyed. It is argued in favor of curricular production methodologies that respect differences as a way to ensure the feeling of belonging to an educational institution attentive to the singularities of its own space.

Keywords: Curriculum policies. Country education. Inclusion.

Resumen: Este articulo pone en discusión las experiencias en lineamientos curriculares en una escuela rural ubicada en un asentamiento del municipio de Nobres - Mato Grosso. El objetivo principal del texto será analizar las propuestas curriculares que buscan articular demandas y saberes locales a las orientaciones dadas por la Base Nacional Común Curricular. Teniendo en cuenta los tiempos de crisis en las ciencias, son centrales los desafios en la inclusión de los estudiantes del campo en un contexto marcado por politicas curriculares que establecen patrones generalizados de saberes, competencias, habilidades y evaluaciones, en nombre de la calidad de la educación. Como referente teórico, se abordan los estudios culturales como marco de análisis para los datos sustraídos de los documentos y de las narrativas de profesores de la escuela investigada. La argumentación, defiende las metodologías de producción curricular que respetan las diferencias como el fortalecimiento del sentimiento de pertenencia en una institución educativa enfocada en las particularidades de su propio espacio.

Palabras clave: Políticas curriculares. Educación rural. Inclusión.

Recebido em 6 de março de 2020

Aceito em 20 de outubro de 2020

\section{FAZENDO DA PESQUISA UMA REDE DE COLABORAÇÃO}

Este artigo deriva das atividades que temos desenvolvido no contexto de um projeto de pesquisa e intervenção que articula pesquisadores vinculados a quatro universidades públicas e professores da educação básica de três estados do Brasil. Tratase de uma produção que, seguindo os objetivos e metas previstas no referido projeto, aposta na potencialidade da rede de pesquisa colaborativa-intersubjetiva a fim produzir alternativas de enfrentamento dos desafios educacionais, no contexto de políticas curriculares homogeneizadoras. Levando em conta que o citado projeto está fundamentado no pressuposto de que é possível produzir política pública para a educação de qualidade, considerando as singularidades dos contextos locais e dos sujeitos envolvidos nos processos curriculares, apresentamos aqui resultados de parte dos estudos que temos desenvolvido no âmbito da Escola Estadual Marechal Cândido Rondon (EECMR), situada no Assentamento CoqueiralQuebó, em Nobres - Mato Grosso, a cerca de $२ २$ Km de Cuiabá. Julgamos imperativo destacar 
que este é um artigo produzido com uma professora da escola (coautora deste texto) e não sobre o trabalho por ela desenvolvido. Ao assumir esse posicionamento, buscamos atender um dos propósitos do projeto, que é a elaboração de textos de divulgação das experiências desenvolvidas por pesquisadores em parceria com docentes nelas envolvidos. Nossa atenção volta-se especialmente à análise de proposições curriculares que buscam articular demandas locais com orientações expressas na Base Nacional Comum Curricular (BNCC) (BRASIL, 2017), visando à inclusão escolar de estudantes do campo.

Para desenvolver as análises sobre as questões relativas à temática pesquisada buscamos amparo teórico em autores que permitem compreender relações entre transformações que se processam na sociedade pós-industrial lem especial no campo da ciência) e demandas apresentadas nas políticas curriculares postas em circulação. 0 material empírico foi extraído de fontes documentais e de histórias de vida contadas por cinco professores da referida escola.

A opção por histórias de vida baseia-se na ideia de que as narrativas (orais e/ ou escritas) têm dimensões formativas e investigativas, uma vez que potencializam tanto o autoconhecimento como a compreensão dos fenômenos estudados. Fundamenta-se, portanto, no reconhecimento de que "histórias de vida, narrativas, memórias, autobiografias, mundo da vida, experiência e voz dos sujeitos passaram a fazer parte de um léxico sobre políticas de formação e currículo", pois essa metodologia "traz a experiência subjetiva para a pesquisa, assim como a para o próprio fazer da educação." (MLLER; MACED0, 2018, p. 952).

Partindo desses pressupostos, organizamos este texto em quatro seções. Inicialmente, recorremos às contribuições teóricas de Lyotard (2013) para tecer algumas considerações sobre o cenário no qual protagonizamos a história do nosso tempo, que foi denominado por ele condição pós-moderna. Consideramos que a crise observada dentro da ciência afeta diretamente a ideia de verdade anunciada pelo lluminismo e, por conseguinte, a educação, uma vez que os referenciais que adotamos para organizar o currículo escolar foram herdados da modernidade. Após as considerações sobre a crise da ciência moderna, deslocamos essa discussão para o campo das políticas curriculares a fim de visualizar o lugar atribuído à ciência e ao saber narrativo (da tradição popular) na BNCC que orienta a produção de currículos em todo Brasil. Nesse sentido, recorremos às contribuições teóricas de autores que pesquisam a produção de currículos com base nos estudos culturais (LOPES, 2006, 2008, 2015; MACED0, 2006, 2015, 2016, 2017; 2019; PINAR, 2016). Considerando que a escola do campo está enredada às políticas curriculares nacionais, buscamos compreender os posicionamentos do povo do campo em relação à educação. Adotamos como referência o Documento-síntese do Seminário da articulação nacional: Por uma educação básica do campo (NERY, 1999), por considerar que tal documento expressa o posicionamento dos movimentos sociais e de pesquisadores da área (ARROYO; FERNANDES, 1999; FERNANDES, 2004; CALDART, 
2003, 2009). Na última seção, apresentamos os resultados de nossas análises sobre proposições curriculares que buscam articular demandas locais com orientações expressas na BNCC e no Documento de Referência Curricular para Mato Grosso DRC-MT (MATO GROSSO, 2018). Nossa atenção volta-se especialmente para os desafios da inclusão de estudantes do campo em um contexto marcado por políticas curriculares que estabelecem competências homogeneizadoras e padrões generalizados de avaliação de performances, em nome da qualidade do ensino

Esclarecemos que a inclusão é concebida, aqui, como o sentimento de pertencimento dos estudantes à comunidade escolar e não apenas como uma possibilidade de estarem matriculados numa escola genérica que ignora as suas diferenças sociais, culturais, linguísticas e identitárias. Entendemos também que o direito de acesso à educação é uma importante conquista dos grupos sociais historicamente excluídos e, por essa razão, precisa ser preservado. No entanto, é premente considerar que "escola para todos não é sinônimo de mesma escola." (SÁ, 2011, p. 13). Em outras palavras, frequentar o mesmo espaço não é sinônimo de inclusão. "0 que resolve é deslocar o foco do ambiente e colocar o foco no estudante, na pessoa. 0 que resolve é envidar todos os esforços para maximizar o aprendizado, é tornar a escola significativa para todos." (SÁ, 2011, p. 17).

\section{CIÊNCIA, PÓS-UERDADE E CURRÍCULO ESCOLAR}

Nesse início de século XXl, produzimos uma complexa história que exige revisão radical das referências que adotamos para ver e agir no mundo, pois os metarrelatos que herdamos da modernidade estão em convulsão. Isso explica porque Lyotard (2013) caracteriza o nosso tempo como condição pós-moderna. A palavra condição é empregada por ele para caracterizar um estado, uma circunstância que é marcada por alterações nas regras dos jogos da política, da ciência, da literatura e das artes em decorrência dos avanços no campo cibernético, informático e informacional, bem como da reconfiguração do capitalismo, que agora mostra sua face mais cruel, retirando direitos dos trabalhadores e exigindo performances heteromorfas compatíveis com a lógica da competitividade vigente no mundo de hoje.

Nosso interesse pela obra de Lyotard reside no fato de que suas análises ajudam a compreender o modo como o saber vem sendo produzido, distribuído e legitimado no contexto do capitalismo contemporâneo e, por conseguinte, as implicações dessas transformações no campo da educação. Esse autor entende de que a sociedade pós-industrial promove mudanças nos postulados da ciência moderna não apenas pela constatação de que a racionalidade 
técnica não ofereceu garantias das benesses anunciadas pelo iluminismo, mas também pelo fato de que a busca da verdade deixou de ser o escopo principal da atividade científica.

Na perspectiva do autor, a ciência é, hoje, um jogo de linguagem imprevisível realizado com base em enunciados heterogêneos apresentados como lances. Cada lance busca desestabilizar o sistema, oferecendo um sentido diferente do existente. As regras são estabelecidas a partir da produção de consenso que define quais saberes poderão ser inscritos, quem poderá jogar e como jogar. "0 consenso não é senão um estado das discussões e não o seu fim. Este é antes a paralogia" (LYOTARD, 2013, p. 118), ou seja, "um lance, de importância muitas vezes desconhecida de imediato, feito na pragmática dos saberes" (LYOTARD, 2013, p. १1-११), que permite alterar as regras e montar um novo jogo. Se os consensos são sempre provisórios e conjunturais, a tese da validade universal dos conhecimentos científicos deixa de ter sentido.

A competitividade instaurada no mundo globalizado faz da ciência uma tecnologia intelectual da chamada força de produção utilizada pelo capital e pelo Estado. Ela é hoje uma mercadoria, um conjunto de mensagens que podem ser traduzidas em quantidade de informação (bits) para alimentar os sistemas informacionais do mundo produtivo. Como mercadoria, a ciência deixa ser legitimada pela prova empírica e pelo debate entre conhecimento verdadeiro/falso, desinteressado/interessado, justo/injusto. "0 que está em questão não é a verdade, mas o desempenho, ou seja, a melhor relação input/out put." (LYOTARD, 2013, p. 83). 0 erro não é desconsiderado, mas sim localizado e analisado, em face da compreensão de ele pode aumentar a eficácia do sistema.

Ao participar de um jogo da ciência sob bases economicistas pautadas na eficiência e na competitividade, o cientista já não pode se apresentar como um herói abnegado, contumaz e devotado à busca da verdade para a emancipação e o progresso humano. Agora ele sabe que precisa se comportar como qualquer outro trabalhador que é instigado a ser um empreendedor de si mesmo, ou seja, alguém que busca melhorar a própria performance para vender suas competências e habilidades no competitivo mundo da produção globalizada.

Se a ciência é uma mercadoria, a sua legitimidade não é apenas epistemológica (de ordem interna). Ela é também sociopolítica (de ordem externa), pois implica decisões governamentais dos Estados-nações e dos atores econômicos interessados não somente na exploração de matérias-primas e de mão de obra qualificada e menos onerosa, mas, especialmente, em participar da competitividade mundial pelo poder científico-tecnológico. "Assim encontra-se aberto um novo campo para as estratégias industriais e comerciais e para as estratégias militares e políticas." (LYOTARD, 2013, p. 5).

A condição pós-moderna não altera, portanto, as intrincadas relações entre ciência e poder engendradas desde a modernidade. Ao invés disso, elas tendem a acentuar 
os conflitos, uma vez que as grandes potências mundiais investem, cada vez mais, em tecnologias sofisticadas para exercer controle político-econômico. Sendo a ciência uma mercadoria de alto valor comercial, as desigualdades cognitivas tornam-se naturalizadas e articuladas com as desigualdades sociais. Naturalizam-se também as históricas cisões entre a ciência e os saberes tradicionais, visto que estes continuam não tendo valor mercadológico. Conforme observou Lyotard, o saber narrativo ${ }^{3}$ reconhece o valor do saber científico, porém, a recíproca não é verdadeira. No campo da ciência o saber narrativo foi e continua sendo considerado inferior, primitivo, subdesenvolvido, atrasado. "No melhor dos casos, tentar-se-á fazer penetrar a luz neste obscurantismo, civilizar, educar, desenvolver." (LYOTARD, 2013, p. 49).

Entendemos que, na obra em pauta, Lyotard desenvolveu análises sobre a ciência na condição pós-moderna com base em suas constatações. Ele não se mostrou interessado na formulação de proposições teórico-metodológicas para enfrentamento dos problemas gerados pela transformação da ciência numa força de produção. Ele não busca acalmar nossas inquietudes e angústias apresentando-nos um novo paradigma capaz de desfazer os nós da racionalidade técnica e as cisões entre saber científico e o saber narrativo. Em outras palavras, ele não apresenta estratégias de enfrentamento dos problemas epistemológicos da denominada sociedade do conhecimento e não vislumbra a emancipação humana pela via da ciência pós-moderna. Contudo, suas análises indicam que a condição pós-moderna instiga nossa imaginação e criatividade para lidar com os desafios do nosso tempo. Instiga também a visualização de outras possibilidades de cognição e de procedimentos, notadamente quando se trata do papel dos professores diante das demandas do mundo globalizado.

Do nosso ponto de vista, o desafio da revisão e redefinição dos nossos referenciais torna-se ainda mais imperativo nesses dias em que constatamos que não estamos apenas diante de uma crise do paradigma da ciência, mas também diante de uma crise mais ampla que envolve dimensões políticas, sociais e culturais. Esse é um tempo em que termos como direitos humanos, democracia, justiça social, justiça cognitiva, ética, respeito ao ambiente, à vida, às identidades e às diferenças são realçados no ideário progressista. Ao mesmo tempo, o ideário conservador legitima as desigualdades sociais e fomenta a máxima exploração do trabalhador e da natureza em nome do desenvolvimento econômico. Isso pode ser observado nos discursos que justificam reformas que retiram direitos trabalhistas, promovem desmatamentos, queimadas, expansão da fronteira agrícola e uso deliberado de agrotóxicos. Entre os conservadores, misoginia, homofobia, xenofobia, discriminação racial, de credo e de cultura são toleradas e reconhecidas como estratégias para recuperar valores patriarcais considerados imprescindíveis para manter a estabilidade político-econômica-social. 
Paradoxalmente, a posse e porte de armas pelo cidadão de bem é defendida como uma política capaz de dar combate à violência no campo e nas cidades, aumentando, assim, as possibilidades de genocídios da população mais vulnerável.

Esse quadro de adoecimento do sentido das palavras explica porque o nosso tempo está sendo denominado era da pós-verdade. Conforme explica Mesquita (2018, p. 33), a expressão pós-verdade foi conceituada em 2016 na Universidade de Oxford como "um substantivo que se relaciona ou denota circunstâncias nas quais fatos objetivos têm menos influência em moldar a opinião pública do que apelos à emoção e a crenças pessoais." Hoje, a rede virtual de comunicação serve não apenas para facilitar a circulação de informações, conhecimentos, imagens e notícias, mas também para difundir fake news que dão azo às práticas de lawfare que (re)configuram a geopolítica do mundo permanentemente. As confusões epistêmicas geradas pelo léxico das redes sociais põem em risco a democracia nas nações mais pobres e, por conseguinte, o cumprimento de acordos internacionais como a declaração universal dos direitos humanos e o acordo internacional sobre mudanças climáticas. 0 pressuposto de imparcialidade da justiça se tornou questionável em face do reconhecimento de que

\footnotetext{
[..] não dá para denunciar um inocente nem para inventar um fato inexistente sem ser desmentido em seguida, mas é perfeitamente possivel não denunciar um culpado e ignorar um fato existente sem ser necessariamente acusado de mentir. Não se pode esconder impunemente uma denúncia levada a uma redação, mas pode-se facilmente escolher a quais dossiês dar-lhe ou não "acesso" e, uma vez dentro das redações, decidir quais serão publicados, cercados ou não de todos os emocionantes recursos de son et lumiere possiveis. Pode-se fazer minguar uma culpa muito grande falando baixo e pouco dela ou inflar uma culpa muito pequena falando alto e insistentemente nela. Pode-se "relacionar", "envolver" ou "ligar" fortemente alguém a alguém, mesmo que essa ligação seja tênue e fortuita, com a mera justaposição de matérias. Pode-se descontextualizar um fato para fazê-lo parecer o que não é, condenar à não existência midiática alguém que vive de voto, brincar com a inversão da relevância do que alguém disse ou deixou de dizer até fazer do sujeito o avesso de si mesmo. Pode-se promover o linchamento moral de quem não declamar pela cartilha "correta" até que a mentira deixe de ser uma questão moral e se transforme numa questão de sobrevivência, expediente do qual guardam uma memória atávica os povos que viveram sob escravidão ou sob regimes de terror. E pode-se levar esse medo - seja da execução fisica, seja da execução moral ou econômica - a tais extremos que até evidências materiais ou biológicas "deixem de existir". (MESQUITA, 2018, p. 37).
}

Ao tecer essas considerações sobre o cenário de crises no qual protagonizamos a nossa história, intentamos chamar atenção para os desafios apresentados aos que pesquisam e/ou atuam no campo da educação. Do nosso ponto de vista, não é possível 
definir projetos educativos sem considerar quais são os posicionamentos assumidos diante desse conturbado quadro que caracteriza a condição pós-moderna.

\section{QUAL É O LUGAR DA CIÊNCIA E DO SABER NARRATIUO NAS POLÍTICAS DE CURRÍCULO?}

Ao reafirmarmos a ideia de que os postulados da ciência moderna precisam ser questionados, notadamente pelos que atuam no campo da educação, não estamos negando a relevância dessa forma de conhecimento como parte da cultura humana. 0 conhecimento científico foi e continua sendo de fundamental importância na nossa vida. No entanto, é imperativo pensar no sentido que atribuímos à ciência, bem como no lugar que ela ocupa no currículo escolar, conforme proposição defendida por Lopes e Macedo (2012).

Discutir o lugar da ciência e do saber narrativo no campo da educação exige considerar que o currículo é espaço-tempo de fronteira cultural (MACED0, 2006). Nessa acepção, a cultura é um entre-lugar e o currículo é tudo o que cerca os contextos educativos e neles acontece, incluindo dimensões políticas, sociais, culturais, históricas, de gênero e de raça. (MLLER; MACED0, 2018, p. 949). É, portanto, lugar de encontro, de embates, de hibridismos, de significação e de ressignificação de saberes.

Entendemos que o escopo de fazer do currículo um espaço-tempo fronteira cultural nesses tempos em que as políticas educacionais promovem reformas sob postulados neoliberais é um grande desafio. Isso porque tais reformas arrefecem proposições progressistas para colocar os currículos escolares nos trilhos das tradições instrumentais (LOPES, 2006). No Brasil, esse fenômeno se revela na produção de textos oficiais que buscam homogeneizar política educacional, a exemplo dos Parâmetros Curriculares Nacionais (PCN), das Orientações Curriculares Nacionais (OCN), das Diretrizes Curriculares Nacionais (DCN) e da Base Nacional Comum Curricular (BNCC). Esses textos, produzidos sob o pressuposto da qualidade da educação, fazem a defesa da aprendizagem, entendida como aquisição de competências e habilidades individuais para aprender a aprender e a fazer uso do aprendido em situações concretas e desafiadoras do mundo globalizado.

A BNCC (BRASIL, 2017, p. 5) foi apresentada às escolas como uma "referência nacional comum e obrigatória para a elaboração dos seus currículos e propostas pedagógicas, promovendo a elevação da qualidade do ensino com equidade." Trata-se de uma política curricular que busca orientar os rumos da Educação Básica no País em todos os entes federados, observando as particularidades regionais e locais. Essa padronização do currículo é fundamentada no discurso dos "direitos de aprendizagem, expressos em dez competências 
gerais, que guiam o desenvolvimento escolar das crianças e dos jovens desde a creche até a etapa terminal da Educação Básica." (BRASIL, 2017, p. 5). Para efetivar essa política o poder público assume a tarefa de estabelecer quais saberes fazem parte da base comum como direitos de aprendizagem de todos os estudantes. À escola de educação básica cabe a tarefa de efetivar o que foi estabelecido oficialmente e complementar o currículo com a parte diversificada "exigida pelas características regionais e locais da sociedade, da cultura, da economia e dos educandos." (BRASIL, 2017, p. 11).

Esse posicionamento unidirecional da política curricular fundamenta-se na crença de que existe um conjunto de saberes homogêneos (de base científica) que devem ser traduzidos em competência e habilidades compatíveis com a epistemologia no mundo globalizado. Fundamenta-se, também, na ideia de que a observância dos direitos de aprendizagem por todas as escolas cria condições democráticas para a realização de avaliações de larga escala realizadas em âmbito estadual, nacional e internacional.

\footnotetext{
Desde as décadas finais do século $\mathrm{XX}$ e ao longo deste início do século XXl, o foco no desenvolvimento de competências tem orientado a maioria dos Estados e Municípios brasileiros e diferentes países na construção de seus currículos. É esse também o enfoque adotado nas avaliações internacionais da Organização para a Cooperação e Desenvolvimento Econômico (OCDE), que coordena o Programa Internacional de Avaliação de Alunos (Pisa, na sigla em inglês), e da Organização das Nações Unidas para a Educação, a Ciência e a Cultura (Unesco, na sigla em inglês), que instituiu o Laboratório Latino-americano de Avaliação da Qualidade da Educação para a América Latina (LLECE, na sigla em espanhol). (BRASIL, 2017, p. 13).
}

Com base nos resultados dessas avaliações são estabelecidas classificações e hierarquizações que expressam o desempenho dos estudantes e das instituições educativas. Hoje, cada escola deve orientar suas ações tendo como referência seu posicionamento no Índice de Desenvolvimento da Educação Básica (IDEB). Como os saberes locais/narrativos não são considerados nas avaliações padronizadas eles podem tornar-se apenas um adereço, uma singularidade de cada contexto escolar, ocupando um lugar periférico e irrelevante.

Observamos que o texto da BNCC mescla discursos de viés político-social ligualdade, diversidade, equidade, participação política e social, liberdade, justiça social, solidariedade, sustentabilidade, protagonismos de estudantes, realidade/cultura local) com discursos de viés economicista (competências, habilidades, capacidade para fazer uso dos aprendizados em situações concretas, mundo do trabalho, etc.) As demandas postas em circulação são, em muitos casos, antagônicas e conflituosas, remetendo "muito mais a conflito do que a consenso, muito mais a produção de sentidos e movimentos diferentes do que a definição de universalismos categóricos e de regras de organização." (LOPES, 2015, p. 448). 
Esse fato dá evidências de quão complexa é a política, o que faz dela uma produção sempre instável, provisória e sujeita a recontextualizações.

Do nosso ponto de vista, a definição de currículos padronizados e articulados a um sistema de avaliação em escala (estadual, nacional e internacional) parece querer corresponder à ideia da existência de uma roupa que cabe em qualquer corpo, em qualquer situação. lgnora-se, assim, que

estamos fadados à heterogeneidade que não permite afirmar, seja por merecimento, necessidade ou direito, quais saberes são/serão passiveis de estar conectados a essas múltiplas singularidades [...] Cada contexto implica a possibilidade de outra leitura, outro texto, outra possibilidade de ser. (LOPES, 2015, p. 457).

Em se tratando de políticas de inclusão escolar é premente considerar:

0 universalismo repousa e sempre repousará, senão em exclusões, pelo menos na indiferença em relação a certas particularidades que ameaçam à abstração. 0 triunfo do indivíduo universal como representação de todos é produzido pelo esquecimento do sujeito concreto que ameaça a pureza da representação - negros, mulheres, pobres, homossexuais, judeus, nordestinos, a depender do momento histórico. [...] a diferença cultural é aceita no âmbito privado, mas a representação política, o cidadão, segue sendo pensado em termos abstratos. [...] Não são apenas os 'diferentes' que são privados de suas vidas para se enquadrarem na mesmidade universal, todos perdem o seu direito à diferença ao serem integrados na promessa do todos como um. (MACED0, 2015, p. 897-898).

Ao tecermos essas considerações sobre o lugar da ciência nas políticas curriculares, buscamos reiterar a ideia que a escola é espaço de aquisição de conhecimentos herdados da cultura geral. Todavia, é preciso ter presente que a escola é, antes de tudo, espaço de convivência, de encontro, de troca, de significação e ressignificação de saberes que compõem a nossa cultura. Ela é lugar de exercício de alteridade, posto que "a educação que reduz o outro ao mesmo ou ao já sabido mata a si própria." (MLLER; MACED0, 2018, p. 962). Esse entendimento é de fundamental importância quando se trata da educação do campo, conforme será discutido a seguir. 


\section{A EDUCAÇÃO QUE INTERESSA AO POUO DO CAMPO}

No Brasil, estudos que tratam da educação do campo (HENRIQUES et al., 2007; NASCIMENTO, 2006) revelam que, durante muito tempo, o povo que vive em espaços rurais ficou à margem das políticas educacionais. Esse fato está relacionado ao pressuposto de que $\mathrm{o}$ trabalho do camponês requer mais força fisica que atividade intelectual. Essa ideia, de fundamento patriarcal, fomentou a produção de estereótipos que serviram para negar, desqualificar e subjugar os que não adotam os padrões de vida urbano.

A luta pela educação que interessa ao povo do campo não é recente. No entanto, ela ganhou vitalidade no contexto da redemocratização do país, notadamente em 1998, quando foi realizada a primeira Conferência Nacional: Por uma Educação Básica do Campo. Esse evento foi uma iniciativa das seguintes entidades: Movimento dos Trabalhadores Rurais Sem Terra (MST); Conferência Nacional dos Bispos do Brasil (CNBB); Universidade de Brasilia (UnB); e Fundo das Nações Unidas para a Infância (UNICEF). 0 propósito foi criar espaços para reflexões, debates e deliberações a partir de encaminhamentos realizados nos encontros estaduais que antecederam a referida conferência (ARROYO; FERNANDES, 1999).

0 reconhecimento da potencialidade daquele evento motivou a continuidade do movimento para dar-lhe mais organicidade. Foi criada então a Articulação Nacional por uma Educação Básica do Campo, com sede em Brasília. Essa inciativa fomentou a elaboração do Documento-síntese do Seminário da articulação nacional por uma educação básica do campo (NERY, 1999). Nesse documento, foram explicitados valores, princípios, objetivos e práticas da Educação Básica do Campo (EBC).

Ao desenvolvermos nossas análises sobre o referido documento, observamos que os valores expressam preocupação com o desenvolvimento humano para fomentar solidariedade, sobriedade, cultivo da memória histórica, indignação diante das injustiças, autoconfiança, entreajuda, esperança. Esses posicionamentos foram defendidos como uma contraposição aos valores anti-humanos forjados na sociedade capitalista os quais induzem ao individualismo, consumismo, conformismo e presenteísmo (desprezo pelo passado). Os princípios explicitam sentidos atribuídos à EBC como uma postura política em favor do povo do campo, dos seus saberes e modos de vida. Os objetivos seguem essa mesma perspectiva, realçando o propósito de potencializar o movimento da EBC pela realização de eventos e pela produção de referenciais teórico-metodológicos sintonizados com os valores e princípios desejados. As práticas fundamentam-se na ideia de que a EBC precisa ser pautada pela formação de sujeitos sociais que valorizam as histórias de vida, os conhecimentos e experiências do povo do campo. Nesse sentido, a prática é vista como locus para repensar 
o realizado, compartilhar novas ideias, (re)criar propostas educativas e promover mudanças (NERY, 1999).

Pesquisadores que têm apoiado o movimento pela EBC (ARROYO; FERNANDES, 1999; FERNANDES, 2004; CALDART, 2003, 2009) contrapõem-se ao antigo modelo de ensino que coloca a escola do campo a serviço do desenvolvimento urbano-industrial. As críticas estão relacionadas ao fato de que o objetivo maior desse tipo de educação é fixar os filhos dos camponeses nos respectivos locais de origem para frear o fluxo migratório campo-cidade. Nesse tipo de educação para o campo o movimento de produção de currículos ocorre de fora para dentro, tendo como referência a cultura urbana. lgnoram-se, assim, as singularidades da vida, da cultura, os interesses e demandas locais.

A educação do campo fundamenta-se não apenas no direito do povo ser educado no campo. Refere-se especialmente a um projeto educativo pensado a partir do campo como um movimento ligado à vida das pessoas que nele vivem. Nessa conceituação, o campo é

\footnotetext{
[...] lugar de vida, onde as pessoas podem morar, trabalhar, estudar com dignidade de quem tem o seu lugar, a sua identidade cultural. 0 campo não é só o lugar da produção agropecuária e agroindustrial, do latifúndio e da grilagem de terras. 0 campo é espaço e território dos camponeses e dos quilombolas. É no campo que estão as florestas, onde vivem as diversas nações indigenas. Por tudo isso, o campo é lugar de vida e sobretudo de educação. (FERNANDES, 2004, p. 137).
}

Como território de produção da vida, o campo é também cenário de luta pela terra. Nele, as demandas dos grupos sociais fragilizados confrontam com demandas dos grandes latifúndios fortemente ligados aos centros do poder político e econômico. As desigualdades na correlação de forças requerem que os grupos sociais mais fragilizados se mantenham em permanente movimento para fazer valer seus direitos à vida e à educação.

A escola do campo precisa se configurar, portanto, como um movimento potencializador de ideias, debates e projetos pedagógicos que levem em conta as singularidades e demandas locais primando pela "sustentabilidade ambiental, agrícola, agrária, econômica, social, política e cultural, bem como a equidade de gênero, étnico-racial, intergeracional e a diversidade de orientação sexual." (HENRIQUES et al., 2007, p. 36).

A luta de educadores e representantes dos movimentos sociais para garantir os postulados da EBC pode ser observada nos espaços de produção das políticas educacionais. Tais postulados aparecem, por exemplo, em textos curriculares, como as Diretrizes Operacionais para a Educação Básica nas Escolas do Campo, instituídas por meio da Resolução CEB/CNE N. ${ }^{1} 1 / 2002$ (BRASIL, 2002). Esse texto da legislação pode ser considerado uma conquista do 
movimento social do campo, uma vez que faz a defesa do direito à educação sintonizada ao contexto em que ela se processa.

\section{PRODUÇÃO DE CURRÍCULO EM UMA ESCOLA DO CAMPO: DESAFIOS DE INCLUSÃO}

Nesta seção trazemos para o debate a questão central colocada em pauta neste estudo: análise de proposições curriculares da escola pesquisada no que diz respeito às articulações entre demandas/saberes locais e orientações expressas na Base Nacional Comum Curricular, em tempos de crise na ciência. Nossa atenção volta-se especialmente para questões relativas à inclusão de estudantes do campo levando em conta a realidade por eles vivenciada e os saberes locais.

0 material empírico para o desenvolvimento das análises foi extraído do Projeto Político-Pedagógico (PPP) da escola pesquisada (EEMCR, 2019), de anotações de conversas com os professores nos encontros de formação promovidos como atividade do projeto de pesquisa e intervenção inovadora e de narrativas feitas por cinco professores da referida escola. Na coleta de dados solicitamos que cada narrador falasse ou escrevesse livremente sobre suas experiências como estudantes e/ou como professor da escola do campo, bem como sobre seu posicionamento em relação a forma como a escola está organizando e desenvolvendo o currículo na perspectiva da inclusão, no quadro de políticas educacionais homogeneizadoras. As narrativas foram gravadas em áudio e transcritas para texto. Os narradores fizeram questão de serem identificados pelo próprio nome porque se reconhecem como sujeitos históricos. Antes de apresentarmos os resultados das nossas análises sobre a temática central deste estudo julgamos ser necessário tecer algumas considerações sobre a história do Assentamento Coqueiral-Quebó e da Escola.

De acordo com Gugelmin (2014), o Assentamento Coqueiral-Quebó foi criado oficialmente em 1986, para instalar 750 famílias. 0s 52.000 hectares de terra foram divididos em comunidades que foram assim denominadas: Córrego Fundo; Água Doce; Lagoa Azul; Roda d'água; Salobra; Xurupita, Setecentos Hectares; Quebó da Mata; Cerquinha; Água Fria; Bom Jardim; Cuiabazinho e Campo Verde. Bom Jardim e Roda d'água se tornaram as comunidades de maior porte em decorrência da proximidade com a rodovia que liga o assentamento à capital e à cidade de Nobres. Ambas dispõem de pequenos comércios (de alimentos, materiais de construção, medicamentos, combustíveis), igrejas de diversas denominações, agências de turismo, cartório, posto de saúde e escolas públicas. 
As narrativas sobre a origem do assentamento falam da vida de pessoas simples que lutaram e lutam pela posse da terra para produzir a subsistência ${ }^{4}$. As histórias mesclam sentimentos de força, solidariedade, ternura, mas também de dor e indignação diante de práticas de negação de direitos e de opressão. Isso explica porque, durante a produção das narrativas, foi necessário dar pequenas pausas para que o narrador pudesse secar as lágrimas, respirar fundo e reestabelecer a fluência da voz. É imperativo ressaltar que os primeiros assentados enfrentaram a força policial, tiveram suas propriedades destruídas (barracos e roçados), foram despejados e levados para um estádio de futebol situado no município de Nobres. Os relatos apresentados a seguir permitem compreender parte dessa história.

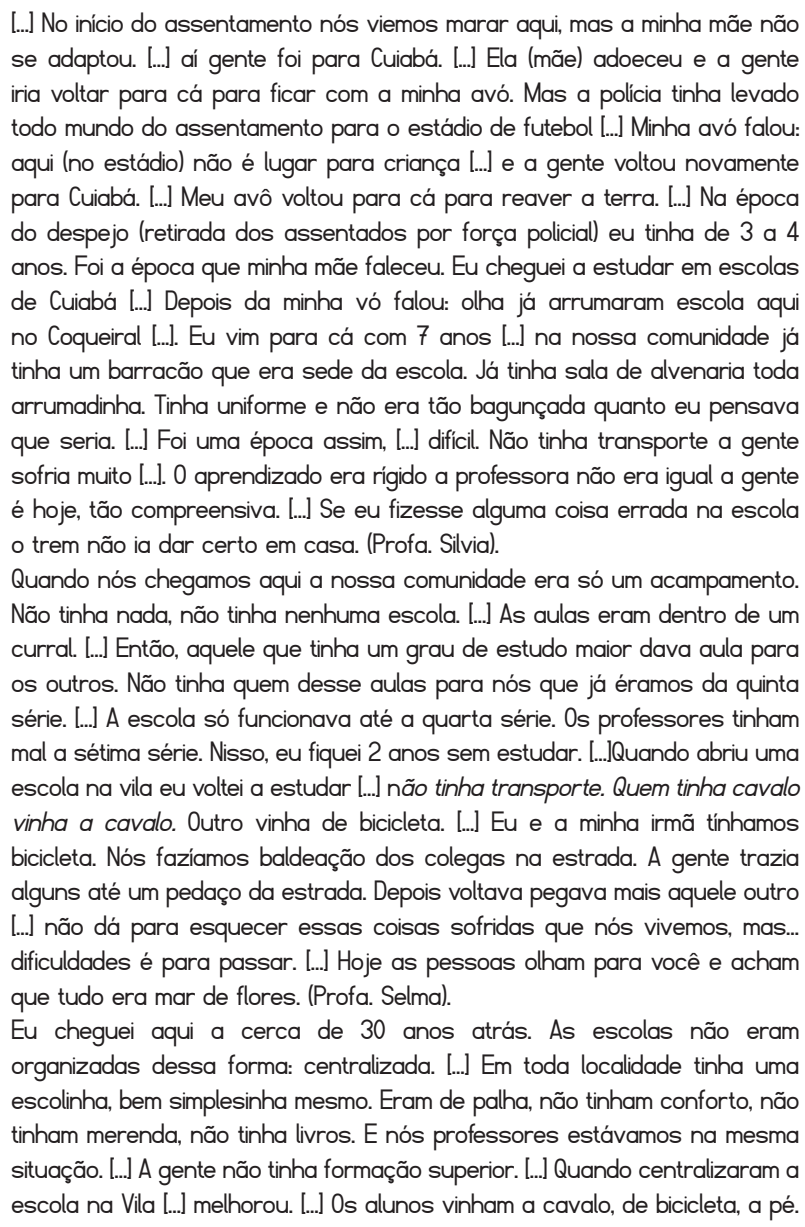

Até a data de realização deste estudo a posse da terra no assentamento não estava efetivamente regularizada pelo Incra. 
Quem tinha mais condições vinha de Jeep. [...] Quando construiram a escola municipal foi possível ofertar o Ensino Médio porque o município permitiu que ○ Estado também ocupasse a escola. (Prof. Noell) (informações verbais).

Essas falas revelam a importância dada à escola pelos primeiros assentados, fato que expressa entendimento de que a luta pela terra deve ser acompanhada pela luta por outros direitos: "ao trabalho, à justiça, à igualdade, ao conhecimento, à cultura, à saúde e à educação." (ARROYO; FERNANDES, 1999, p. 12). As histórias sobre a formação profissional dos narradores revelam também que a luta é mais árdua quando se trata do acesso à educação superior.

Quando eu terminei o Ensino Médio fiquei mais cinco anos sem acesso nenhum até que surgiu a oportunidade da educação a distância [...] (numa universidade particular). [.... Eu fiz Serviço Social, mas na realidade o meu sonho era estudar Direito. Eu sempre gostei de leis [...]. Serviço Social era o que mais se aproximava do Direito. [...] Depois que eu terminei o curso não tinha oportunidade de exercer a profissão por aqui. [...] surgiu a oportunidade de fazer uma complementação pedagógica em Sociologia, porque tem relações com Serviço Social [...]. Depois eu fiz a Pedagogia. [...] Eu trabalhei três anos na secretaria da escola até que, em 2017, surgiu a oportunidade de dar aula de Sociologia e Filosofia. (Profa. Selma).

$\mathrm{Na}$ época eu iniciei no curso de matemática. [...] lofertado por uma universidade particular). E ai por problemas que aconteceram eu fui obrigado a parar. Só em 2018 eu consegui recursos para concluir o curso superior e a especialização. [...] Nós ficávamos uma semana lá e voltávamos para trabalhar aqui com os alunos, para fazer os estudos e as pesquisas e ai a gente retornava para socializar os resultados, de dois em dois meses. Aí a gente voltava. É a mesma experiência da Pedagogia da Alternância que muitas vezes é proposta para a escola, mas gera uma grande rejeição por parte até mesmo da própria comunidade. (Prof. Noel) (informações verbais).

Outro aspecto realçado nas narrativas foi a história conturbada da EEMCR. A criação oficial dessa instituição se deu em 2004, antes da existência de um prédio próprio. A princípio, ela funcionou na escola municipal, fato que explica a adoção do mesmo nome, diferindo apenas da sua identificação: estadual. A mudança para instalações próprias se deu em 2011. Três anos após a inauguração o prédio foi interditado, em decorrência de problemas estruturais que colocaram em risco a vida dos estudantes e professores. A partir de então, escola passou a funcionar em oito contêineres, instalados na lateral direita do prédio. A quadra de esportes também foi interditada.

Mesmo em contêineres, a escola manteve a oferta do Ensino Regular e da Educação de Jovens e Adultos (EJA), a fim de garantir aos estudantes do Ensino Fundamental $\|$ e do Ensino Médio o direito de acesso à educação. A inclusão foi apontada no PPP (ESCOLA ESTADUAL MARECHAL CÂNDIDO RONDON, 2019) como um grande desafio uma vez que a escola 
integra estudantes trabalhadores do campo, indígenas, transexual, pessoas com deficiência e surdos. Na escola, o Atendimento Educacional Especializado (AEE) é feito em uma sala de recursos multifuncionais com presença de intérprete de Língua Brasileira de Sinais (Libras).

Para assegurar o acesso aos estudantes oriundos das várias comunidades a escola conta com dez ônibus escolares que percorrem rotas com trajetos complexos e distâncias diferenciadas (de até $90 \mathrm{Km}$ ). A rota mais distante permite o acesso de um estudante indígena (etnia Bakairi), cujos pais trabalham em uma fazenda da região. Em época de chuva os problemas de transporte se acentuam, repercutindo no tempo escolar. $\mathrm{Na}$ escola, os que estudam no período diurno recebem refeições diárias no horário do almoço. 0s que estudam no período noturno recebem refeições no jantar.

Em 2019, o quadro docente da escola estava constituído por 27 professores que dispunham de formação compativel à área de atuação. Alguns professores atuavam também nas salas anexas que funcionam numa escola municipal de Bom Jardim. Para motivar a formação de seus professores a escola realizou encontros de estudos semanais em conformidade com orientações da Secretaria de Estado de Educação (Seduc). Alguns encontros foram desenvolvidos em articulação com as atividades do projeto de pesquisa e intervenção inovadora.

A integração entre professores visando ao protagonismo dos estudantes nas atividades pedagógicas foi buscada por meio do desenvolvimento de projetos de incentivo à leitura de livros, à criação e manutenção da horta escolar, à economia solidária e à Arte. 0 projeto de arte está centrado em três vertentes: dança circular, teatro e coral de vozes e Libras. A importância das atividades artísticas para a inclusão foi explicada pela coordenadora desse projeto.

\footnotetext{
Outra forma que nós tivemos de incluir nossos alunos surdos foi o Projeto Coral de Libras "Mãos que Encantam", pois realizamos esse projeto juntamente com os alunos ouvintes. Através do Projeto Coral conseguimos na escola no projeto educ'arte apoiado pela Seduc. São três modalidades: dança circular coral e teatro. 0 coral integra 120 componentes e a dança circular 53. No teatro nós tivemos muita procura, por isso nós fizemos por sala. Cada sala apresenta uma peça teatral durante o semestre. No projeto o aluno não só aprende a cantar com as mãos. Aprende também sinais para se comunicar com aluno surdo. (Profa. Helen) (informação verbal).
}

Nas narrativas sobre o coral Mãos que encantam ficou evidente que a inclusão não é pensada de forma unidirecional, ou seja, como inserção do surdo na cultura ouvinte. Ela é pensada como um lugar de encontro, de troca, de coexistência, uma vez que instiga o ouvinte a se imiscuir na cultura surda. Dessa forma, a comunicação em Libras não fica restrita ao surdo-intérprete. 0 estudante surdo pode se comunicar com alguns de seus 
pares e professores ouvintes na língua de sinais. Difunde-se, assim, a ideia de que as línguas não são meros fenômenos culturais em que os povos encontram a sua identidade; são também o lugar em que o conhecimento está inscrito (MIGNOL0, 2006, p. 669).

Os projetos desenvolvidos pela escola buscam também incluir estudantes das salas anexas a fim de superar o sentimento que eles têm de não pertencimento à escola em que estão matriculados e muito menos à escola que empresta o espaço, uma vez que ela tem nome diferente do que eles devem escrever nos cadernos e nas provas. Há entre professores entendimento de que tais estudantes têm razão para dizer: "não sou daqui", "não sou de lá", "não tenho escola".

Um aspecto que chamou nossa atenção foi o lugar de destaque que a escola dá às Tecnologias Digitais da Informação e da Comunicação (TDICs). Esse fato faz com que professores que chegam da cidade assumam outro conceito de escola do campo.

\begin{abstract}
Sou professora de Artes [... Sempre morei na zona urbana e comecei a trabalhar como professora na escola Urbana. [... na experiência aqui, a princípio, fiquei apreensiva. Sempre ouvia falar que a educação no campo é precária tinha muitas dificuldades, por exemplo, falta de material pedagógico, de espaço, etc. Mas foi completamente equivocada a visão que eu tinha da escola do Campo. Aqui me deparei com muitos materiais pedagógicos e de apoio. Vou citar alguns exemplos: Xbox, lousa digital, computadores, TVs, data show, etc. Foi aqui na escola do campo que tive meus primeiros contatos com vários multimídia que ainda não havia tido na escola Urbana. (Profa. Helen) (informação verbal).
\end{abstract}

Esse relato remete ao reconhecimento de que a escola do campo não é um tipo de escola inferior e à margem dos recursos tecnológicos da sociedade pós-industrial. Como qualquer outra escola, elas têm singularidades que variam de um lugar para outro. 0 que caracteriza a escola do campo é o compromisso com o protagonismo do estudante como parte de um povo em movimento pelos seus direitos.

Na sua origem, o 'do' da Educação do campo tem a ver com esse protagonismo: não é 'para' e nem mesmo 'com': é dos trabalhadores, [...] Um 'do' que não é dado, mas que precisa ser construído pelo processo de formação dos sujeitos coletivos, sujeitos que lutam para tomar parte da dinâmica social, para se constituir como sujeitos políticos, capazes de influir na agenda política da sociedade. Mas que representa, nos limites 'impostos pelo quadro em que se insere', a emergência efetiva de novos educadores, interrogadores da educação, da sociedade, construtores (pela luta/pressão) de políticas, pensadores da pedagogia, sujeitos de práticas. (CALDART, 2009, p. 42). 
0 Projeto Político-Pedagógico da escola aponta a necessidade do currículo estar voltado à realidade do campo para que o aluno se reconheça como protagonista da história do lugar onde mora. No entanto, não observamos no citado documento referências aos fundamentos da educação do campo. Do nosso ponto de vista esse distanciamento dos pressupostos defendidos pelos movimentos sociais parece ser motivado tanto pelo intento de ajustar o PPP às orientações apontadas na BNCC e no DRC-MT como pelo desejo de promover uma educação atenta às expectativas dos estudantes e dos pais.

\begin{abstract}
Nossa escola é um arremedo de educação do campo, pois o conteúdo é urbano. [...] Os livros são urbanos. [...] Nossos alunos estão tão focados na escola urbana que nossas metodologias voltadas para o campo não os atraí. Eles querem o celular de última geração. Estão com a mente urbana, embora sejam trabalhadores do campo. [..] Até mesmo os pais não querem conteúdo do campo. Eles querem que os filhos sejam doutores. Eles têm amor pelo campo, mas a mentalidade é de agronegócio. (Prof. Noel) (informação verbal).
\end{abstract}

Os descompassos entre as proposições pedagógicas do professor e as expectativas dos estudantes e dos pais reiteram a ideia de currículo como uma "conversa complicada", tal como concebe Pinar (2016, p. 19).

\footnotetext{
É uma conversa - esforços de entendimento por meio da comunicação - entre alunos e professores, individuos que efetivamente existem em determinados lugares e dias, [...]. 0 fato de alunos e professores serem individuos complica consideravelmente a conversa, e frequentemente de formas desejáveis, em razão de cada pessoa trazer para o que estiver sendo estudado seu conhecimento prévio, suas circunstâncias atuais, seu interesse e, sim, seu desinteresse. A fala e os textos dos alunos permitem que os professores avaliem em que pé estão as conversas em sala de aula, o que pode acontecer em seguida, o que precisa ser revisto ou as vezes evitado.
}

Observamos que, em 2019, o planejamento dos professores estava sendo feito a partir da incorporação de trechos da BNCC e do DRC-MT, que explicitam o que deve ser observado em termos de: competências específicas a serem desenvolvidas; práticas adotadas; habilidades; objetos de conhecimento (conteúdos, conceitos e processos). A autoria do professor era demandada apenas na explicitação dos: conhecimentos prévios necessários; materiais; procedimentos, tecnologias e recursos utilizados; processos de aplicação/fixação e síntese/avaliação. "Dessa forma, a suposta participação docente assume a forma de responsabilização por um projeto que já está traçado de antemão: um projeto de reconhecimento, em que não há espaço para o imponderável." (MACED0, 2017, p. 543). 
Lopes (2008, p. 205), com base nas ideias de Lyotard, considera que a lógica das atuais políticas curriculares tira a apropriação de conteúdos científicos do foco central do processo educativo. "Estes são compreendidos como passíveis de serem acessados em bases de dados variadas, mas facilmente acessíveis pela transformação das informações de nossas bibliotecas em bytes."

As avaliações ocorrem no âmbito local (dentro das disciplinas), estadual (Avalia MT) e nacional (Prova Brasil, Olimpíadas das diversas áreas do conhecimento, Exame Nacional do Ensino Médio). A preocupação com o desempenho nas avaliações externas, sobremaneira com o que é revelado no IDEB da escola, arrefece o interesse pelas articulações com as demandas e saberes locais. Destarte, os saberes narrativos (da tradição popular) tendem a ser obliterados ou tratados apenas como adereços do currículo, uma vez que não integram o rol dos saberes mensurados nas avaliações.

Observamos que, se por um lado a política oficial limita a autonomia do professor sobre a produção do currículo, por outro, ela instiga a adoção de práticas pedagógicas que fomentem o protagonismo do estudante. Espera-se que ele tenha consciência "de seu papel social pela construção de uma autonomia intelectual que o permita a aprender constantemente." (MATO GROSSO, 2019). Nessa orientação oficial, a autonomia intelectual é associada à capacidade de aprender a aprender, ou seja, capacidade de fazer a gestão da própria aprendizagem. Esse termo passa a ser entendido como

\footnotetext{
[...] habilidade individual de recuperar e guardar informação, construir novo conhecimento baseado em conhecimento anterior, mover passo a passo em hierarquias estruturais supostamente inerentes ao saber disciplinar, usar estratégias metacognitivas e demonstrar compreensão e transferência de aprendizagem. (TAUBMAN, 2009, p. 181-182 apud MACED0, 2017, p. 543).
}

Nas narrativas o protagonismo dos estudantes foi relacionado diretamente à adoção de metodologias ativas articuladas com as tecnologias digitais, conforme foi defendido no DRC-MT. Tais metodologias exigem que o professor se coloque na relação pedagógica como um mediador que faz uso de estratégias pedagógicas pautadas em problematizações que motivem a construção coletiva do conhecimento com os estudantes, levando em conta a realidade local (MATO GROSSO, 2018, p. 36).

0 DRC-MT chama muito a atenção para as metodologias ativas e para a realidade do aluno [...]. Eu concordo com essa metodologia. [...] Nós fizemos entrevistas sobre a educação do campo com a professora Gerti que foi uma das primeiras moradoras do assentamento. Nossos alunos perceberam - quanto a história dela é interessante. Foi emocionante ver o que eles colocaram no papel. Depois nós convidamos a professora para vir aqui. Eles 
fizeram a leitura do que ela contou. Ela ficou muito emocionada e alegre também. [... Para mim, essa metodologia foi um grande aprendizado. [...] Com outra turma eu desenvolvi um projeto sobre piscicultura. [...] Mas eu vejo que o saber do campo não é valorizado pelos estudantes. É mais para quem tem identidade com o campo, que tem amor à terra. É assim que eu vejo [...] Eu não vi muita diferença da BNCC em relação ao que a gente vinha fazendo. (Prof. Noel).

Eu trabalho com projetos para incluir hábitos e costumes da comunidade ao que é proposto pela BNCC e pelo DRCMT. É extremamente importante e eficaz, pois é um meio de unir aquilo que é proposto pelos documentos de referência com a realidade local. Ao pensar desta forma surgiram vários projetos no percurso, como o das Rotas Escolares, pois através do mesmo conseguiremos compreender o percurso e o pensar do aluno a caminho da escola, compreender exatamente quanto tempo e quantos quilometros enfrenta todos os dias até a chegada a escola. Através da utilização do aplicativo mobile Wikiloc ${ }^{5}$ os alunos aprenderam a utilizar a tecnologia e, assim, criar e gravar o percurso da escola até a sua casa. Com estes dados a professora de Geografia [...] trabalha objetos de conhecimento (conteúdos) de sua disciplina com a realidade vivida por eles no dia a dia resinificando a prática. Através dos relatos escritos do percurso, consigo trabalhar os objetos de Língua Portuguesa e inserir a produção textual em uma prática social, pois consigo formular situações reais para uma prática simulada em sala, além disso consigo notar as perspectivas de cada um e em determinados momentos trabalhar questões de interesse diversos, construindo um elo entre o que eles querem aprender com o que é necessário ensinar. (Profa. Mariana) (informações verbais).

Observamos que o DRC-MT faz referência a conceitos, como: território, territorialidade, identidade, traços simbólicos e indenitários, reconhecendo que a escola é espaço de pluralidade. No que diz respeito à educação do campo, o documento sugere que ela seja organizada como uma prática pedagógica do, no e para o campo, estabelecendo diálogos entre os conhecimentos empíricos (da população local) e os conhecimentos científicos difundidos pela escola (MATO GROSSO, 2018, p. 68-69). É realçado o entendimento que, no Mato Grosso, o campo é cenário de relações de poder entre dois grupos sociais distintos: empresários do agronegócio e pequenos produtores. No entanto, as diferenças no modo de produção não são problematizadas, mantendo silêncio em relação aos postulados da educação do campo defendida pelos movimentos sociais.

0 compromisso com a sustentabilidade e a defesa do meio ambiente expressos na BNCC, no DRC-MT e no PPP da escola foi outro aspecto realçado nos relatos dos professores. No cotidiano da escola é comum ouvir comentários sobre a expansão das lavouras de soja na região e sobre aumento do consumo de agrotóxicos. É evidente a preocupação com a manutenção das nascentes, uma vez que o turismo é uma das fontes de renda da comunidade. Esse posicionamento reafirma a ideia de que "os conceitos relacionados

0 Wikiloc é um site que oferece trilhas gratuitas de GPS e waypoints que permitem envios e compartilhamentos. 
à sustentabilidade e à diversidade complementam a educação do campo ao preconizarem novas relações entre as pessoas e a natureza e entre os seres humanos e os demais seres dos ecossistemas." (HENRIQUES et al., 2007, p. 13).

Apesar da complexidade do quadro educacional nesses tempos de pós-verdade, o ano de 2020 traz novos ânimos para professores e estudantes da escola pesquisada. lsso porque, após cinco anos de funcionamento em containers, a reforma está sendo concluída. Finalmente, a escola voltará a funcionar no lugar que the é de direito e que oferece espaços específicos para administração, sala de professores, biblioteca, laboratório de informática, salas de aula, sala de recursos multifuncionais para Atendimento Educacional Especializado (AEE), cozinha, refeitório, quadra de esportes, saguão para circulação e eventos.

\section{CONCLUINDO}

Falar da produção de currículo em escolas do campo dando centralidade à inclusão exige considerar que o campo está inserido nas intrincadas relações econômicas, políticas, sociais e culturais do mundo globalizado. Por essa razão, as escolas do campo estão sujeitas às mesmas demandas das políticas curriculares apresentadas às escolas urbanas. Elas também estão orientadas pelas competências (performances) estabelecidas previamente pelos poderes constituídos, fato que restringe o poder de decisão dos professores e estudantes sobre o processo educativo. Por conseguinte, a ideia de educação do campo fundada no respeito às diferenças de tempos, de organização do espaço, de modos de ser e de viver dos camponeses vai sendo apagada para dar lugar à educação instrumental, que faz do estudante um empreendedor de si mesmo. Assim, a escola do campo vai se distanciando dos postulados do projeto de sociedade defendido pelos movimentos sociais, ou seja, do projeto social que articula desenvolvimento econômico com sustentabilidade do ambiente, justiça social, justiça cognitiva, respeito às diferenças e inclusão dos grupos minoritários historicamente excluídos.

A chegada das tecnologias digitais da informação e da comunicação no campo tem exigido novos posicionamentos político-pedagógicos por parte de seus professores. É preciso reconhecer que o fato de os estudantes do campo terem possibilidades de acesso às novas tecnologias não sublimam o papel do professor, posto que o acesso às informações e conhecimentos que circulam nas mídias digitais não significa aprendizagens e possibilidades de formação humana em sua acepção mais ampla.

Em suma, nesses tempos em que as políticas curriculares engendradas em escala internacional buscam fazer de cada estudante um empreendedor de si mesmo torna-se 
imperativo recuperar a ideia de educação (da cidade e do campo) como a "experiência de estar o outro." (MACED0, 2017, p. 539). Nessa perspectiva, não é prudente produzir políticas curriculares que unificam as diferenças, porque somos seres singulares, limitados, incompletos e insuficientes. Somos seres relacionais e dependentes do mundo na sua inteireza. Precisamos da água, do ar, da terra, das demais espécies vivas e, notadamente, de outras pessoas. Enfim, precisamos compreender o sentido das palavras do poeta pantaneiro Manoel de Barros: "sabedoria pode ser que seja ser mais estudado em gente do que em livros." (BARROS, 2010, p. 375).

\section{REFERÊNCIAS}

ARROYO, M. G.; FERNANDES, B. M. A educação básica e o movimento social do campo. Brasilia, DF: Coordenação da Articulação Nacional Por uma Educação, 1999. Disponivel em: http://educampo.miriti.com. br/arquivos/Biblioteca/0081.pdf. Acesso em: 10 out. 2019.

BARROS, M. Poesia completa. São Paulo: Leya, 2010.

BRASIL. Ministério da Educação. Base Nacional Comum Curricular. Brasilia: MEC, 2017. Disponivel em: http://basenacionalcomum.mec.gov.br/images/historico/BNCC_EnsinoMedio_embaixa_site_110518.pdf. Acesso em: 4 out. 2019.

BRASIL. Resolução CEB/CNE N. $1 / 2002$. Institui Diretrizes Operacionais para a Educação Básica nas Escolas do Campo. Brasilia, DF: [s. n.], 3 abr. 2002. Disponível em: http://portal.mec.gov.br/. Acesso em: 7 nov. 2019.

CALDART, R. S. A escola do Campo em Movimento. Currículo sem Fronteiras, v. 3, n. 1, p. 60-81, jan./jun. 2003. Disponivel em www.curriculosemfronteiras.org. Acesso em: 22 out. 2019.

CALDART, R. S. Educação do campo: notas para uma análise de percurso. Revista Trabalho Educação Saúde, v. 7, n. 1, p. 35-64, 2009.

ESCOLA ESTADUAL MARECHAL CÂNDIDO RONDON. Projeto Político Pedagógico. Nobres: SEDUC, 2019.

FERNANDES, B. M. Diretrizes de uma Caminhada. In: ARROYO, M. G. et al. Por uma educação do campo. 2. ed. Petrópolis: Vozes, 2004. p. 27-36.

GUGELMIN, G. M. M. C. Educação do Campo: uma análise do diálogo entre saber escolar e saber local no contexto do Programa Projovem. 2014. Dissertação (Mestrado em Educação) - Instituto de Educação, Universidade Federal do Mato Grosso, 2014. Disponivel em: https://ri.ufmt.br/handle/1/294. Acesso em: 4 dez. 2019.

HENRIQUES, R. et al. (org.). Educação do campo: diferenças mudando paradigmas. Cadernos Secad, fev. 2007. Disponivel em: http://livros01.livrosgratis.com.br/me4531.pdf. Acesso em: 22 out. 2019. 
LOPES, A. C. Discursos nas políticas de currículo. Currículo sem Fronteiras, v. 6, n. 2, p. 33-52, jul./dez. 2006. Disponivel em: http://www.curriculosemfronteiras.org. Acesso em: 20 nov. 2019.

LOPES, A. C.; MACEDO, E. Currículo e Cultura: o lugar da ciência. In: LBBÂNEO, J. C.; ALVES, N. (org.). Temas da Pedagogia. São Paulo: Cortez, 2012. p. 152-166.

LOPES, A. C. Por que somos tão disciplinares? Educação Temática Digital, v. 9, p. 201-233, 2008. Edição Especial. Disponível em: https://nbnresolving.org/urn:nbn:de:0168-ssoar-72891. Acesso em: 10 jan. 2020.

LOPES, A. C. Por um currículo sem fundamentos. Linhas Críticas, v. 21, n. 45, p. 445-466, maio/ago. 2015. Disponivel em: https://www.redalyc.org/pdf/1935/193542556011.pdf. Acesso em: 10 jan. 2020.

LYOTARD, J. F. A condição pós-moderna. 15. ed. Tradução: R. C. Barbosa. Rio de Janeiro: José Olímpio, 2013.

MACEDO, E. Base Nacional Comum para Currículos: direitos de aprendizagem e desenvolvimento para quem? Educação \& Sociedade, v. 36, n. 133, p. 891-908, dez. 2015. D0l: https://dx.doi.org/10.1590/ ES0101-73302015155700.

MACEDO, E. Base Nacional Curricular Comum: a falsa oposição entre conhecimento para fazer algo e conhecimento em si. Educação em Revista, v. 32, n. 2, p. 45-68, jun. 2016. D0l: https://dx.doi. org/10.1590/0102-4698153052.

MACEDO, E. Currículo como espaço-tempo de fronteira cultural. Revista Brasileira de Educação, v. 11, n. 32, p. 285-296, ago. 2006. D0l: https://dx.doi.org/10.1590/S1413-24782006000200007.

MACEDO, E. Fazendo a Base virar realidade: competências e o germe da comparação. Revista Retratos da Escola, v. 13, n. 25, p. 39-58, jan./maio 2019.

DOl: https://dx.doi.org/10.22420/rde.v13i25.967. Disponivel em:

http://retratosdaescola.emnuvens.com.br/rde/article/view/967. Acesso em: 4 nov. 2019.

MACEDO, E. Mas a escola não tem que ensinar? Conhecimento, reconhecimento e alteridade na teoria do currículo. Currículo sem Fronteiras, v. 17, n. 3, p. 539-554, set./dez. 2017. Disponível em: https:// www.curriculosemfronteiras.org/voll7iss3articles/macedo.pdf. Acesso em: 7 out. 2019.

MATO GROSSO. Documento de Referência Curricular para Mato Grosso: concepções para a Educação Básica. Cuiabá: Seduc, 2018. Disponível em: https://drive.google.com/file/d/12ldfeadygzglyA2FnyYBOtpH ZiYSJw9p/view. Acesso em: 11 dez. 2019.

MESQUITA, F. L. A pós-verdade levará à pós-democracia? Revista USP, n. 116, p. 31-38, jan./mar. 2018. D0l: https://doi.org/10.11606/issn.2316-9036.v0i116p31-38. 
MIGNOLO, W. Os esplendores e as misérias da "ciência": colonialidade, geopolítica do conhecimento e pluri-versalidade epistêmica. In: SANTOS, B. de S. (org.). Conhecimento Prudente para uma vida Docente. Um discurso sobre as ciências revisitado. 2. ed. São Paulo: Cortez, 2006. p. 667-709.

MLLER, J. L.; MACEDO, E. Políticas públicas de currículo: autobiografia e sujeito relacional. Práxis Educativa, v. 13, n. 3, p. 948-965, set./dez. 2018. D0l: https://doi.org/10.5212/PraxEduc.v.13i3.0018.

NASCIMENTO, C. G. Educação e cultura: as escolas do campo em movimento. Fragmentos de Cultura, v. 16, n. 11/12, p. 867-883, nov./dez. 2006. D0l: http://dx.doi.org/10.18224/frag.v16i1112.184.

NERY, I. J. Documento-síntese do seminário da articulação nacional por uma educação básica do campo. In: ARROYO, M. G.; FERNANDES, B. M. (org.). A educação básica e o movimento social do campo. Brasília, DF: Coordenação da Articulação Nacional Por uma Educação do Campo, 1999. p. 37-43.

PINAR, W. Estudos curriculares: ensaios selecionados. São Paulo: Cortez, 2016.

SÁ, N. de. Escolas e classes de surdos: opção político-pedagógica legítima. In: SÁ, N. de (org.). Surdos: qual escola? Manaus: Editora Valer e EdUA, 2011. p. 17-61.

Endereço para correspondência: Rua C, 65, Residencial Garden Bosque da Saúde, Torre Il, apto 806, Canjica, 78.050-322, Cuiabá, Mato Grosso, Brasil; tanialima.ufmt@gmail.com 